\title{
Solubilities of cinnamic acid, phenoxyacetic acid and 4-methoxyphenylacetic acid in supercritical carbon dioxide
}

\author{
Yan-Ping Chen*, Yen-Ming Chen, Muoi Tang \\ Department of Chemical Engineering, National Taiwan University, Taipei, Taiwan, ROC
}

\section{A R T I C L E I N F O}

\section{Article history:}

Received 3 May 2008

Received in revised form 5 September 2008

Accepted 8 September 2008

Available online xxx

\section{Keywords:}

Solid solubility

Supercritical carbon dioxide

Correlation

\begin{abstract}
A B S T R A C T
The solid solubilities of cinnamic acid, phenoxyacetic acid and 4-methoxyphenylacetic acid in supercritical carbon dioxide were measured using a semi-flow apparatus. The experiments were taken at 308.2, 318.2 and $328.2 \mathrm{~K}$. The pressure range was from 11 to $24 \mathrm{MPa}$. These data were confirmed as equilibrium solid solubilities based on a plug flow mass transfer model. The solid solubilities were further correlated using the equations of state or semi-empirical models. The correlation results are satisfactory with optimally fitted binary interaction parameters in the Peng-Robinson equation of state.
\end{abstract}

(C) 2008 Elsevier B.V. All rights reserved.

\section{Introduction}

Supercritical technology is widely applied in extraction, chemical reaction and materials processing $[1,2]$ where solid compounds are usually involved in those processes. Solid solubility data in supercritical fluids, especially in carbon dioxide, are essential to the development of the related industrial processes. Solid solubilities in supercritical carbon dioxide are reviewed or collected in recent literature $[3,4]$. It is noticed that more experimental data for organic and pharmaceutical compounds are still needed. The motivation of this study was to measure novel solubility data of solid acid compounds in supercritical carbon dioxide.

We have measured the solubilities of organic and pharmaceutical components in supercritical carbon dioxide using a semi-flow apparatus $[5,6]$. In this study, we applied the same apparatus to measure the solid solubilities of three acidic organic compounds, cinnamic acid, phenoxyacetic acid and 4-methoxyphenylacetic acid, in supercritical carbon dioxide. The experimental temperatures were $308.2,318.2$ and $328.2 \mathrm{~K}$. The pressure range was from 11 to $24 \mathrm{MPa}$. Cinnamic acid and phenoxyacetic acid are used in agriculture and pharmaceutical industries. 4-Methoxyphenylacetic acid is used in organic synthesis and also in pharmaceutical industries. These polar compounds all have the $\mathrm{COOH}$ function group. As far as we know, no solid solubility data for these compounds in supercritical carbon dioxide have been shown in literature.

\footnotetext{
* Corresponding author.

E-mail address: ypchen@ntu.edu.tw (Y.-P. Chen).
}

In this research, we report new experimental data that are useful in process development or theoretical model correlation. The measured results in this study were firstly examined by a plug-flow mass transfer model to ensure that equilibrium solubilities were obtained. The experimental data were then correlated using either the equation of state or semi-empirical models. The correlation accuracy and the optimally fitted model parameters are presented in this study.

\section{Experimental}

\subsection{Chemicals}

Carbon dioxide (component 1) was purchased from San-Fu Chemical Co. (Taiwan) with a minimum purity of 99.8 mass\%. Cinnamic acid and phenoxyacetic acid were purchased from Merck Company, and 4-methoxyphenylacetic acid was purchased from Acros Company. All pure chemicals had a minimum purity of 99 mass\%, and were used without further purification. The properties of these pure components are listed in Table 1 . The critical temperatures and pressures of the three solid compounds were estimated from the Joback correlation equation [7]. The acentric factors were estimated from the Ambrose method [8]. The structures of the three solid components are illustrated in Fig. 1.

\subsection{Experimental apparatus and procedures}

This study applied a semi-flow type apparatus to measure the solid solubilities of three organic compounds. The experimental 
Table 1

Purities and physical properties of the chemicals used in this study.

\begin{tabular}{|c|c|c|c|c|c|c|c|}
\hline Compound & Molecular weight $\left(10^{-3} \mathrm{~kg} / \mathrm{mol}\right)$ & $T_{\mathrm{m}}(\mathrm{K})$ & $\underline{V}^{S}\left(10^{-3} \mathrm{~m}^{3} / \mathrm{mol}\right)$ & $T_{\mathrm{c}}(\mathrm{K})$ & $P_{\mathrm{c}}(\mathrm{MPa})$ & $\omega$ & Purity (mass\%) \\
\hline Carbon dioxide $\left(\mathrm{CO}_{2}\right)$ & 44.010 & - & - & $304.12[16]$ & $7.374[16]$ & $0.225[16]$ & $>99.8$ \\
\hline Cinnamic acid $\left(\mathrm{C}_{9} \mathrm{H}_{8} \mathrm{O}_{2}\right)$ & 148.159 & $406.15[14]$ & $0.1188[14]$ & $803.94[7]$ & $3.858[7]$ & $0.688[8]$ & $>99.0$ \\
\hline Phenoxyacetic acid $\left(\mathrm{C}_{8} \mathrm{H}_{8} \mathrm{O}_{3}\right)$ & 152.148 & $371.65[14]$ & $0.1130[15]$ & $802.61[7]$ & $3.991[7]$ & $0.760[8]$ & $>99.0$ \\
\hline 4-Methoxyphenylacetic acid $\left(\mathrm{C}_{9} \mathrm{H}_{10} \mathrm{O}_{3}\right)$ & 166.173 & $360.15[14]$ & $0.1279[15]$ & 827.30 [7] & $3.485[7]$ & $0.808[8]$ & $>99.0$ \\
\hline
\end{tabular}

apparatus is similar as that in our previous research [5]. It is consisted of three sections for the supply of supercritical $\mathrm{CO}_{2}$, the equilibrium between the solid and the supercritical $\mathrm{CO}_{2}$, and the analyses of the experimental results.

Pure $\mathrm{CO}_{2}$ was firstly liquefied to $272.2 \mathrm{~K}$ and was then pressurized to a desired pressure by a HPLC pump (Thermo Separation Product). The exit pressure was controlled using a back-pressure regulator (Tescom). The high pressure $\mathrm{CO}_{2}$ passed through a preheating coil immersed in a water bath. It reached a specific supercritical state and was then charged into the pre-equilibrium and equilibrium cells. The pre-equilibrium cell had a volume of $150 \mathrm{~cm}^{3}$ where $25 \mathrm{~g}$ solid sample was distributed in five layers of glass beads. The volume of the equilibrium cell was $300 \mathrm{~cm}^{3}$ in which $50 \mathrm{~g}$ of solid sample was distributed in 10 layers. At the ends of both cells, filters were equipped to prevent any entrainment. The experimental temperature and pressure were detected in the equilibrium cell by calibrated thermocouple (Ins Co.) and pressure gauge (Heise Co.), respectively. The accuracies for their readings were $\pm 0.1 \mathrm{~K}$ and $\pm 0.03 \mathrm{MPa}$, respectively.

The supercritical $\mathrm{CO}_{2}$ flew through the equilibrium cell and then expanded to atmospheric pressure after a needle valve. The needle valve was wrapped with a heating tape to keep the temperature above the melting point of the solid by $20-30 \mathrm{~K}$ in order to avoid any precipitation in the line. Solid was separated from the gas phase upon de-pressurization, and was dissolved into a flask with organic solvent of ethyl acetate. The flow rate of the gas was recorded by a wet test meter (Ritter TG1). The solution in the collecting flask was sonicated for more than $10 \mathrm{~min}$. Its composition was measured by a UV-vis spectrometer (Jasco, UV-975). A sharp absorption peak in the UV-vis spectrometer was observed at the wavelength of $254 \mathrm{~nm}$ for cinnamic acid and phenoxyacetic acid, and was at $274 \mathrm{~nm}$ for 4-methoxyphenylacetic acid. Calibrations of the UV measurements were satisfactory with a $R^{2}$ regression coefficient better than 0.999 .
At least three solid solubility data were taken at each experimental temperature and pressure. The uncertainty of experimental measurements was better than $\pm 5 \%$.

\section{Results and discussion}

The experimental solubility data in supercritical $\mathrm{CO}_{2}$ have been examined by applying a fluid-solid mass transfer model [9]. The detail procedures have been presented in our previous work [5]. The basic criterion of this mass transfer model is to calculate the ratio of the measured solid solubility relative to its saturated value, $X=C / C_{\text {sat }}$, under various experimental conditions (temperature, pressure, and flow rate). If the values of $X$ are close to unity, the experimentally measured solid solubilities are accepted as equilibrium data. In our experiments, the $X$ values under various experimental conditions were all greater than 0.999 , and the mass transfer effect is confirmed to be negligible in this study.

The measured solid solubility data in supercritical $\mathrm{CO}_{2}$ for cinnamic acid, phenoxyacetic acid and 4-methoxyphenylacetic acid are presented in Tables $2-4$, respectively. The densities of supercritical $\mathrm{CO}_{2}$ at various experimental conditions were calculated from the Peng-Robinson equation of state [10]. These values were most near to the experimental values from IUPAC, and are also included in these tables. Generally, the solubilities for all three solid compounds increased with pressure at a fixed temperature. At a constant temperature, phenoxyacetic acid showed the largest solubility in supercritical $\mathrm{CO}_{2}$. This may be due to the relatively higher solid vapor pressure as indicated in the following correlation results using equation of state (EOS). Cinnamic acid and 4-methoxyphenylacetic acid had similar and competitive solid solubilities at each experimental temperature. These solid solubility data were further correlated using the equation of state, or semiempirical equation approaches.

Compound
Cinnamic acid
$\left(\mathrm{C}_{9} \mathrm{H}_{8} \mathrm{O}_{2}\right)$
4henoxyacetic acid
$\left(\mathrm{C}_{8} \mathrm{H}_{8} \mathrm{O}_{3}\right)$
4-Methoxyphenylacetic acid
$\left(\mathrm{C}_{9} \mathrm{H}_{10} \mathrm{O}_{3}\right)$

Fig. 1. Structures of solid compounds in this study. 
Table 2

Solubility of cinnamic acid (2) in supercritical $\mathrm{CO}_{2}(1)$.

\begin{tabular}{llll}
\hline$T(\mathrm{~K})$ & $P(\mathrm{MPa})$ & $10^{4} y_{2}$ & $\rho_{1}\left(\mathrm{~kg} / \mathrm{m}^{3}\right)$ \\
\hline 308.2 & 14.91 & 1.23 & 814.04 \\
& 16.85 & 1.78 & 836.73 \\
& 18.99 & 2.00 & 857.44 \\
& 20.99 & 2.40 & 874.00 \\
& 23.12 & 2.47 & 889.50 \\
318.2 & 12.30 & 0.41 & 670.57 \\
& 13.75 & 0.79 & 715.12 \\
& 15.17 & 1.19 & 745.83 \\
& 16.78 & 1.79 & 772.71 \\
& 18.71 & 2.20 & 798.43 \\
& 20.85 & 2.77 & 821.74 \\
328.2 & 23.05 & 3.58 & 841.93 \\
& 12.58 & 0.35 & 546.67 \\
& 14.71 & 0.95 & 645.63 \\
& 16.85 & 1.81 & 701.75 \\
& 18.51 & 2.38 & 732.66 \\
& 20.09 & 2.94 & 756.41 \\
& 21.88 & 3.56 & 778.94 \\
& 23.61 & 4.25 & 797.60 \\
\hline
\end{tabular}

\subsection{Equation of state method}

At solid-supercritical fluid phase equilibrium, the equal fugacity criterion is applied and the solid solubility is expressed as:

$y_{i}=\frac{p_{i}^{\mathrm{vp}} \exp \left[\underline{V}_{i}^{\mathrm{S}}\left(p-p_{i}^{\mathrm{vp}}\right) / R T\right]}{\hat{\phi}_{i}^{\mathrm{SCF}} p}$

where $\underline{V}_{i}^{\mathrm{S}}$ is the solid molar volume, $P_{i}^{\mathrm{vp}}$ is the solid vapor pressure, and $\hat{\phi}_{i}^{\mathrm{SCF}}$ is the fugacity coefficient of solid in the supercritical fluid phase. The solid vapor pressure was expressed by the conventional equation:

$\ln p_{i}^{\mathrm{vp}}=A-\frac{B}{T}$

where $A$ and $B$ were two empirical parameters. Two EOS were employed in this study in data regression: the

Table 3

Solubility of phenoxyacetic acid (3) in supercritical $\mathrm{CO}_{2}$ (1).

\begin{tabular}{llll}
\hline$T(\mathrm{~K})$ & $P(\mathrm{MPa})$ & $10^{4} y_{3}$ & $\rho_{1}\left(\mathrm{~kg} / \mathrm{m}^{3}\right)$ \\
\hline 308.2 & 12.37 & 1.15 & 774.48 \\
& 14.09 & 1.55 & 802.83 \\
& 15.68 & 2.22 & 823.61 \\
17.44 & 2.54 & 842.82 \\
& 19.26 & 2.84 & 859.81 \\
& 20.83 & 3.25 & 872.76 \\
& 22.43 & 3.46 & 884.68 \\
318.2 & 12.58 & 1.06 & 680.80 \\
& 14.16 & 1.81 & 724.91 \\
& 15.02 & 2.15 & 742.96 \\
& 16.61 & 2.67 & 770.16 \\
& 18.44 & 3.51 & 795.15 \\
& 20.02 & 4.52 & 813.21 \\
& 22.02 & 5.03 & 832.87 \\
& 11.75 & & 484.10 \\
& 13.40 & 0.57 & 593.08 \\
& 15.02 & 1.68 & 655.49 \\
& 16.58 & 2.58 & 695.92 \\
& 18.02 & 3.56 & 724.30 \\
& 19.54 & 4.86 & 748.63 \\
& 20.92 & 5.83 & 767.34 \\
& 22.23 & 6.74 & 782.93 \\
\hline
\end{tabular}

Table 4

Solubility of 4-methoxyphenylacetic acid (4) in supercritical $\mathrm{CO}_{2}$ (1).

\begin{tabular}{llll}
\hline$T(\mathrm{~K})$ & $P(\mathrm{MPa})$ & $10^{4} y_{4}$ & $\rho_{1}\left(\mathrm{~kg} / \mathrm{m}^{3}\right)$ \\
\hline 308.2 & 11.61 & 0.51 & 758.80 \\
& 14.30 & 0.99 & 805.82 \\
& 15.68 & 1.37 & 823.61 \\
& 17.75 & 1.59 & 845.89 \\
& 19.26 & 2.08 & 859.81 \\
& 21.13 & 2.25 & 875.08 \\
& 23.61 & 2.78 & 892.81 \\
318.2 & 12.65 & 0.47 & 683.20 \\
& 14.03 & 0.88 & 721.90 \\
& 15.61 & 1.33 & 753.83 \\
& 17.33 & 1.87 & 780.63 \\
& 18.85 & 2.51 & 800.10 \\
& 20.30 & 3.09 & 816.15 \\
& 21.54 & 3.83 & 828.42 \\
& 23.06 & 4.17 & 842.01 \\
& 14.23 & & 628.69 \\
& 15.47 & 0.61 & 668.55 \\
& 17.13 & 0.98 & 707.53 \\
& 18.99 & 1.61 & 740.35 \\
& 20.50 & 2.94 & 761.93 \\
& 22.09 & 4.17 & 781.35 \\
& 23.47 & 5.17 & 796.19 \\
\hline
\end{tabular}

Soave-Redlich-Kwong EOS [11]:

$p=\frac{R T}{\underline{V}-b}-\frac{a}{\underline{V}(\underline{V}+b)}$

and the Peng-Robinson EOS [10]:

$p=\frac{R T}{\underline{V}-b}-\frac{a}{\underline{V}(\underline{V}+b)+b(\underline{V}-b)}$

In these EOS, $\underline{V}$ was the molar volume and the EOS parameters ( $a$ and $b$ ) were determined from the critical constants of the pure compounds. The van der Waals mixing rules (VDW2) with two binary interaction parameters $\left(k_{i j}\right.$ and $\left.l_{i j}\right)$ were used in this study:

$a_{\mathrm{m}}=\sum_{i} \sum_{j} x_{i} x_{j}\left(a_{i} a_{j}\right)^{0.5}\left(1-k_{i j}\right)$

$b_{\mathrm{m}}=\sum_{i} \sum_{j} x_{i} x_{j} \frac{\left(b_{i}+b_{j}\right)}{2}\left(1-l_{i j}\right)$

If parameter $l_{i j}$ was taken as zero and only a single parameter $k_{i j}$ was used, it was denoted as the VDW1 mixing rules. The binary interaction parameters together with the parameters in the solid vapor pressure equation were optimally fitted to the experimental solid solubility data by minimizing the following objective function:

$\mathrm{obj}=\sum_{k} \frac{\left|y_{i, k}^{\exp }-y_{i, k}^{\mathrm{cal}}\right|}{y_{i, k}^{\exp }}$

The summation was over all experimental $k$ th points. The superscripts exp and cal represented the experimental and calculated values, respectively. Table 5 presents the optimally fitted parameters from the EOS method. The binary interaction parameters were taken as temperature-independent and their values are all in reasonable range. Both EOS with the VDW2 mixing rules yielded satisfactory results where the absolute average deviation in solid solubility (AADY) is around $5 \%$.

\subsection{Semi-empirical correlation equation method}

Two commonly used semi-empirical equations were applied in this study for solid solubility data correlation. The Chrastil equation 
Table 5

Correlated results of solubility data in $\mathrm{SCCO}_{2}$ using various EOS mixing rules.

\begin{tabular}{|c|c|c|c|c|c|c|}
\hline \multirow[t]{2}{*}{ Mixing rules } & \multicolumn{3}{|c|}{ Peng-Robinson EOS } & \multicolumn{3}{|c|}{ Soave-Redlich-Kwong EOS } \\
\hline & $k_{1 j}$ & $l_{1 j}$ & $\operatorname{AADY}(\%)$ & $k_{1 j}$ & $l_{1 j}$ & AADY (\%) \\
\hline \multicolumn{4}{|c|}{$\mathrm{CO}_{2}(1)+$ Cinnamic acid $(2)$} & \multicolumn{3}{|c|}{$\ln P_{2}^{\mathrm{vP}}\left(10^{-6} \mathrm{MPa}\right)=40.92-(14527.28 / T(\mathrm{~K}))$} \\
\hline VDW1 & 0.0237 & - & 6.16 & 0.0281 & - & 6.57 \\
\hline VDW2 & 0.0405 & 0.0457 & 5.37 & 0.0457 & 0.0471 & 5.48 \\
\hline \multicolumn{4}{|c|}{$\mathrm{CO}_{2}(1)+$ Phenoxyacetic acid (3) } & \multicolumn{3}{|c|}{$\ln P_{3}^{\mathrm{vp}}\left(10^{-6} \mathrm{MPa}\right)=43.78-(14557.64 / T(\mathrm{~K}))$} \\
\hline VDW1 & 0.1440 & - & 12.14 & 0.1525 & - & 12.92 \\
\hline VDW2 & 0.2311 & 0.2464 & 4.41 & 0.2386 & 0.2530 & 4.73 \\
\hline \multicolumn{4}{|c|}{$\mathrm{CO}_{2}(1)+4$-Methoxyphenylacetic acid (4) } & \multicolumn{3}{|c|}{$\ln P_{4}^{\mathrm{vp}}\left(10^{-6} \mathrm{MPa}\right)=55.95-(21101.81 / T(\mathrm{~K}))$} \\
\hline VDW1 & -0.1438 & - & 14.04 & -0.1381 & - & 13.48 \\
\hline VDW2 & -0.2448 & -0.2663 & 4.80 & -0.2332 & -0.2654 & 5.15 \\
\hline
\end{tabular}

$\operatorname{AADY}(\%)=\frac{100}{n} \sum_{k=1}^{n} \frac{\left|y_{j, k}^{\text {exp }}-y_{j, k}^{\text {cal }}\right|}{y_{j, k}^{\exp }}$

[12] expressed the solid solubility in a three-parameter form $(n, C$, and $D$ ):

$\ln S_{i}\left(\mathrm{~kg} / \mathrm{m}^{3}\right)=n \ln \rho_{1}\left(\mathrm{~kg} / \mathrm{m}^{3}\right)+\frac{C}{T}+D$

$S_{i}=\frac{\rho_{1} M_{i} y_{i}}{M_{1}\left(1-y_{i}\right)}$

Mendes-Santiago and Teja [13] also proposed the following equation that fitted the solid solubility using three parameters $(E$, $F$, and $G)$ :

$T \ln \left(y_{i} P(\mathrm{MPa})\right)=E+F \rho_{1}\left(\mathrm{~kg} / \mathrm{m}^{3}\right)+G T$

The parameters in the above two semi-empirical equations were optimally fitted to the experimental solid solubility data using the same objective function in Eq. (7). Table 6 illustrates the correlation results from the two semi-empirical equations. The grand AADY value over all experimental solubility data was around $8 \%$ that was larger than that from the EOS correlation.

Figs. 2-4 present the experimental data and the calculated results from the Peng-Robinson EOS for three solid compounds, respectively. Satisfactory agreement between measured and correlated results is observed. The cross-over pressures are estimated as 16.2-16.8 MPa for cinnamic acid, 13.4-14 MPa for phenoxyacetic acid, and 16-16.7 MPa for 4-methoxyphenylacetic acid, respectively.

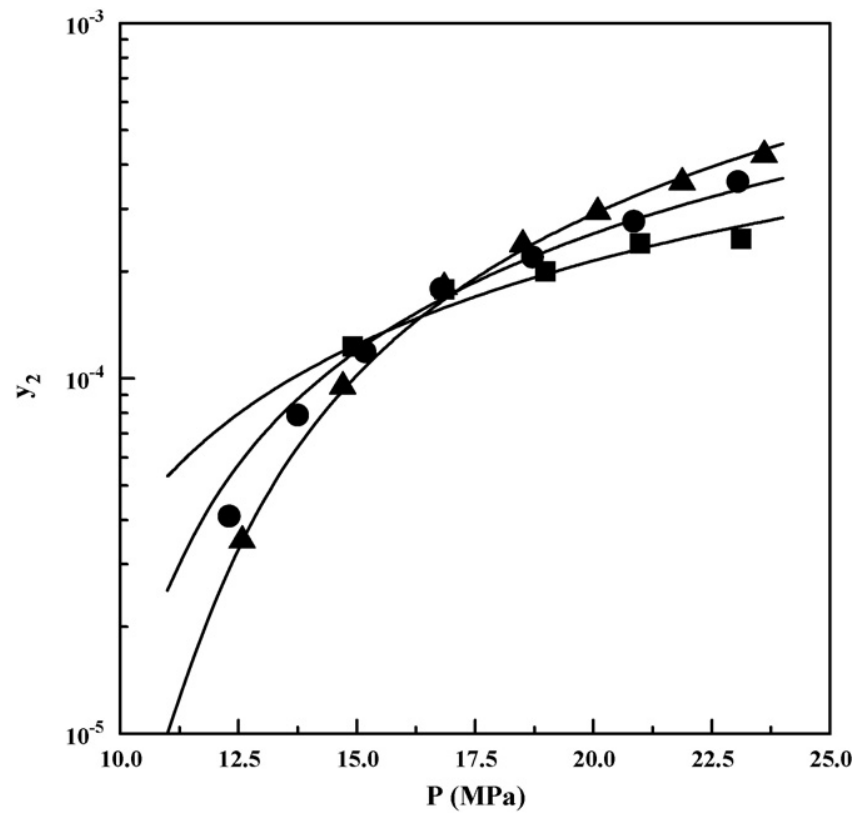

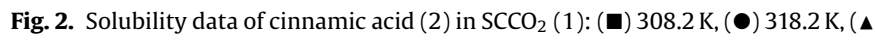
$328.2 \mathrm{~K}$, and (-) Peng-Robinson equation of state with VDW2 mixing rule.

Table 6

Correlated results of the solubility data in $\mathrm{SCCO}_{2}$ using various empirical models.

\begin{tabular}{|c|c|c|c|c|c|c|c|}
\hline \multicolumn{4}{|c|}{ Chrastil equation } & \multicolumn{4}{|c|}{ Mendez-Santiago and Teja equation } \\
\hline$n$ & $C$ & $D$ & $\operatorname{AADY}(\%)$ & $E$ & $F$ & $G$ & $\operatorname{AADY}(\%)$ \\
\hline \multicolumn{8}{|c|}{$\mathrm{CO}_{2}(1)+$ Cinnamic acid (2) } \\
\hline 8.21 & $-6.79 \times 10^{3}$ & -34.00 & 9.28 & $-1.33 \times 10^{4}$ & 4.48 & 25.19 & 8.05 \\
\hline \multicolumn{8}{|c|}{$\mathrm{CO}_{2}(1)+$ Phenoxyacetic acid (3) } \\
\hline 7.78 & $-9.11 \times 10^{3}$ & -23.32 & 10.38 & $-1.54 \times 10^{4}$ & 4.53 & 32.25 & 9.23 \\
\hline \multicolumn{8}{|c|}{$\mathrm{CO}_{2}(1)+4$-Methoxyphenylacetic acid (4) } \\
\hline 11.50 & $-1.02 \times 10^{4}$ & -45.19 & 3.62 & $-1.73 \times 10^{4}$ & 5.58 & 34.84 & 3.87 \\
\hline
\end{tabular}

$\operatorname{AADY}(\%)=\frac{100}{n} \sum_{k=1}^{n} \frac{\left|y_{j, k}^{\text {exp }}-y_{j, k}^{\text {cal }}\right|}{y_{j, k}^{\exp }}$. 


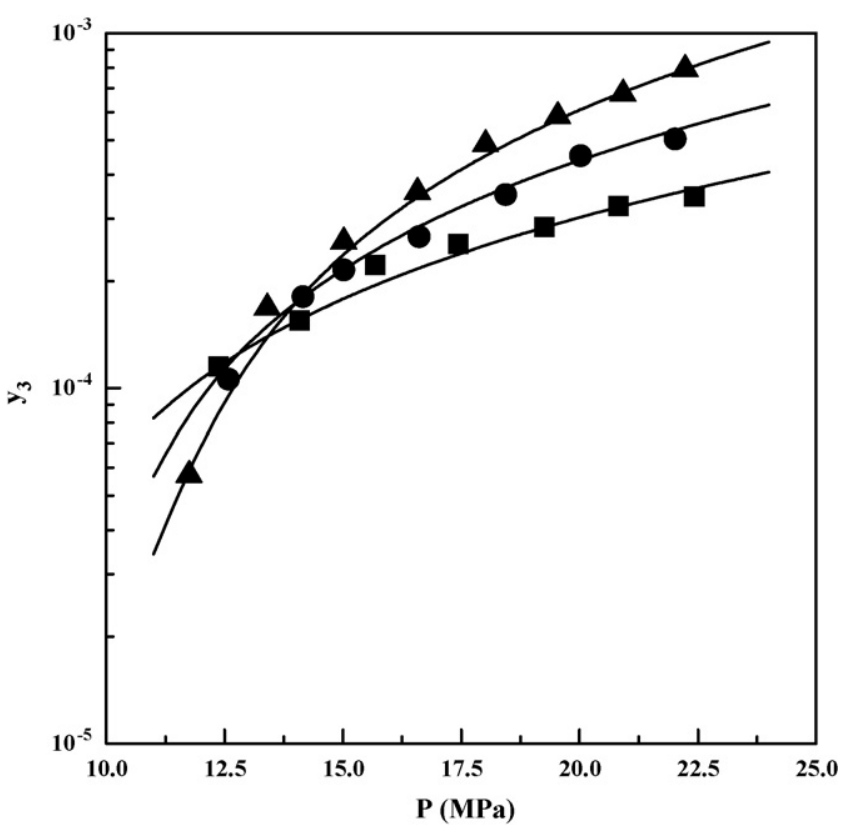

Fig. 3. Solubility data of phenoxyacetic acid (3) in $\mathrm{SCCO}_{2}$ (1): (匹) $308.2 \mathrm{~K}$, (•) $318.2 \mathrm{~K}$, ( $) 328.2 \mathrm{~K}$, and (-) Peng-Robinson equation of state with VDW2 mixing rule.

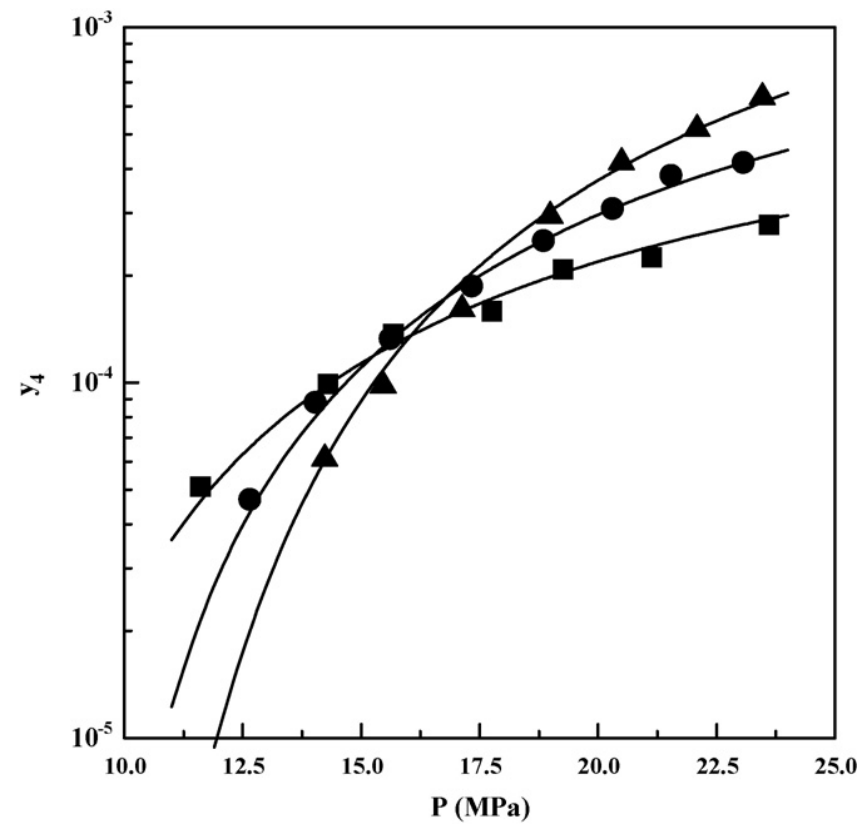

Fig. 4. Solubility data of 4-methoxyphenylacetic acid (4) in $\mathrm{SCCO}_{2}$ (1): (ש) $308.2 \mathrm{~K}$, (•) $318.2 \mathrm{~K},(\mathbf{\Lambda}) 328.2 \mathrm{~K}$, and (-) Peng-Robinson equation of state with VDW2 mixing rule.

\section{Conclusion}

The solid solubilities in supercritical $\mathrm{CO}_{2}$ were measured in this study for cinnamic acid, phenoxyacetic acid and 4methoxyphenylacetic acid. The experimental temperatures were $308.2,318.2$ and $328.2 \mathrm{~K}$ where the pressure ranged from 11 to $24 \mathrm{MPa}$. The mass transfer effect was confirmed to be negligible in this study. The measured data were satisfactorily correlated using the Soave-Redlich-Kwong and Peng-Robinson EOS with VDW2 mixing rules where the absolute average deviation in solid solubility was $5 \%$. The cross-over pressures for these solid compounds were also determined from experimental results.

\section{List of symbols}

$a, b \quad$ parameters in the equation of state

$A, B \quad$ parameters in the solid vapor pressure equation

C parameter in the Chrastil model, or the solid solubility

$D \quad$ parameter in the Chrastil model

$E, F, G$ parameters in the Mendez-Santiago and Teja equation

$k, l \quad$ binary interaction parameters

$M \quad$ molecular weight

$n \quad$ parameter in the Chrastil equation

obj objective function defined in Eq. (7)

$P \quad$ pressure

$P_{\mathrm{C}} \quad$ critical pressure

$R \quad$ gas constant

$S \quad$ solid solubility defined in Eq. (8)

$T$ temperature

$T_{\mathrm{c}} \quad$ critical temperature

$T_{\mathrm{m}} \quad$ melting temperature

$\underline{V} \quad$ molar volume

$\underline{V}^{s} \quad$ solid molar volume

$\bar{X} \quad$ relative saturated concentration of the solid solute

$y \quad$ mole fraction

Greek letters

$\phi \quad$ fugacity coefficient

$\rho$ density

$\omega \quad$ acentric factor

\section{Subscripts}

1 component $1, \mathrm{CO}_{2}$

$i, j \quad$ component $i$ or $j$

$k \quad$ the $k$ th experimental point

m mixture property

sat saturated value

\section{Superscripts}

cal calculated value

exp experimental value

vp vapor pressure

\section{Acknowledgements}

The authors are grateful to the support of this research from the National Science Council, Taiwan, ROC. Experimental work of S.Y. Huang is appreciated.

\section{References}

[1] E. Reverchon, R. Adami, Nanomaterials and supercritical fluids, J. Supercrit. Fluids 37 (2006) 1-22.

[2] M. Bahrami, S. Ranjbarian, Production of micro- and nano-composite particles by supercritical carbon dioxide, J. Supercrit. Fluids 40 (2007) 263-283.

[3] F.P. Lucien, N.R. Foster, Solubilities of solid mixtures in supercritical carbon dioxide: a review, J. Supercrit. Fluids 17 (2000) 111-134.

[4] R.B. Gupta, J.-J. Shim, Solubility in Supercritical Carbon Dioxide, CRC Press, New York, 2007.

[5] S.-Y. Huang, M. Tang, S.L. Ho, Y.-P. Chen, Solubilities of $N$-phenylacetamide, 2methyl- $N$-phenylacetamide and 4-methyl- $N$-phenylacetamide in supercritical carbon dioxide, J. Supercrit. Fluids 42 (2007) 165-171.

[6] C.-S. Su, Y.-P. Chen, Measurement and correlation for the solubility of nonsterodial anti-inflammatory drugs (NSAIDs) in supercritical carbon dioxide, J. Supercrit. Fluids 43 (2007) 438-446.

[7] K.G. Joback, R.C. Reid, Estimation of pure-component properties from group contributions, Chem. Eng. Commun. 57 (1987) 233-243.

[8] D. Ambrose, J. Walton, Vapor pressures up to their critical temperatures of normal alkanes and 1-alkanols, Pure Appl. Chem. 61 (1989) 1395-1403.

[9] A. Abaroudi, F. Trabelsi, F. Recasens, Quasi-static measurement of equilibrium solubilities in SC fluids: a mass transfer criterion, Fluid Phase Equilib. 169 (2000) 177-189. 
[10] D.Y. Peng, D.B. Robinson, A new two-constant equation of state, Ind. Eng. Chem. Fundam. 15 (1976) 59-62.

[11] G. Soave, Equilibrium constants from a modified Redlich-Kwong equation of state, Chem. Eng. Sci. 27 (1972) 1197-1203.

[12] J. Chrastil, Solubility of solids and liquids in supercritical gases, J. Phys. Chem. 86 (1982) 3016-3021.

[13] J. Mendez-Santiago, A.S. Teja, The solubility of solids in supercritical fluids, Fluid Phase Equilib. 158-160 (1999) 501-510.
[14] CRC Handbook of Chemistry and Physics, 87th ed., CRC Press, Boca Raton, FL 2006-2007 (Section 3).

[15] A. Immirzi, B. Perrni, Prediction of density in organic crystals, Acta Crystallogr. A 33 (1977) 216-218.

[16] B.E. Poling, J.M. Prausnitz, J.P. O'Connell, The Properties of Gases and Liquids, 5th ed., McGraw-Hill, New York, 2001 (Appendix A). 